Document downloaded from:

http://hdl.handle.net/10251/149077

This paper must be cited as:

Lavara García, R.; Moce Cervera, ET.; Baselga Izquierdo, M.; Vicente Antón, JS. (2017).

Freezability genetics in rabbit semen. Theriogenology. 102:54-58.

https://doi.org/10.1016/j.theriogenology.2017.07.013

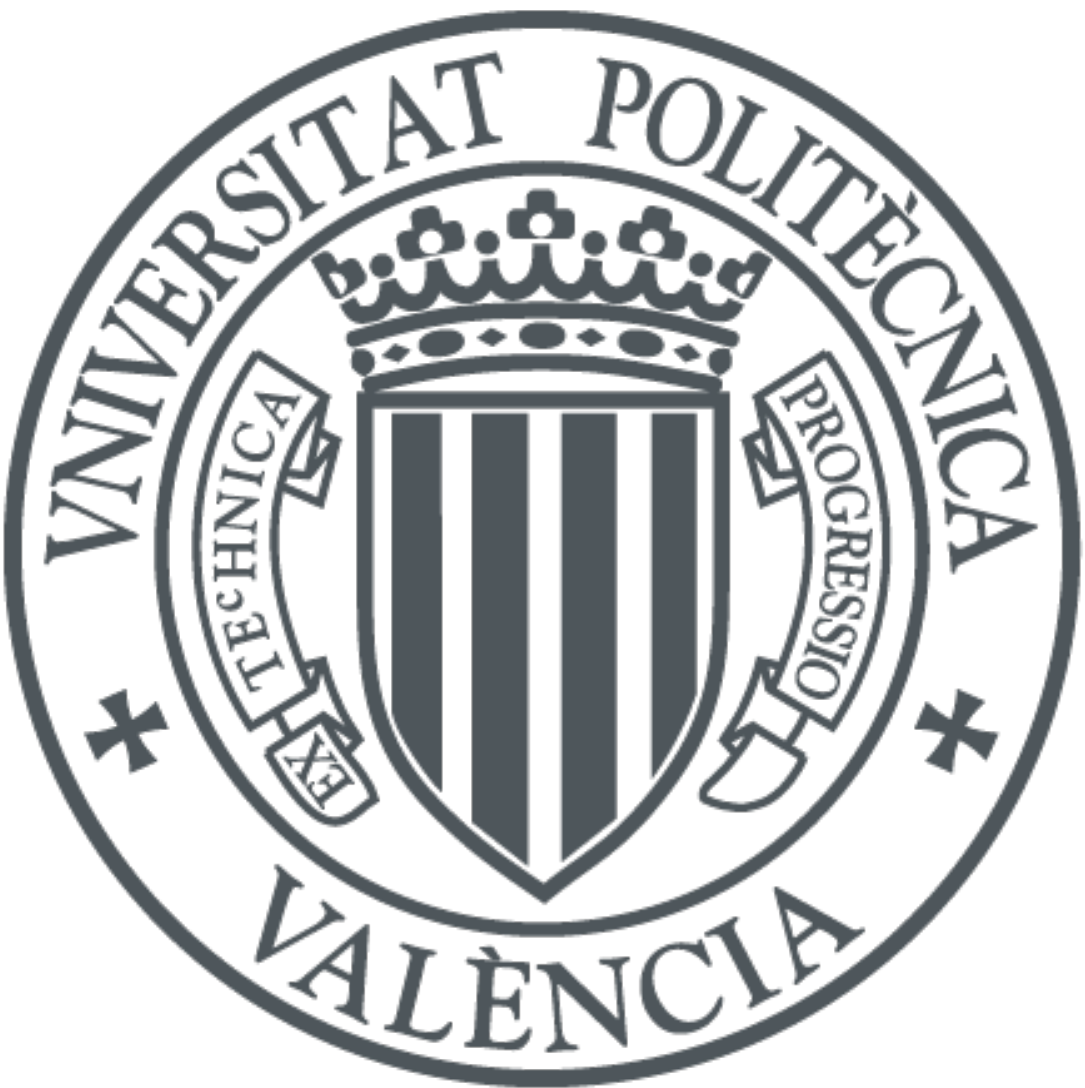

The final publication is available at

https://doi.org/10.1016/j.theriogenology.2017.07.013

Copyright Elsevier

Additional Information 


\section{Freezability genetics in rabbit semen}

Lavara Ra,*, Mocé Eb, Baselga Mc, Vic ente J Sc

3 aGrupo Fisiopatología de la Reproducción, Dpto. PASAPTA, Facultad de Veterinaria,

4 Universidad Cardenal Herrera-CEU, CEU Universities, Spa in

5 bInstituto Valenciano de Investigaciones Agrarias, Centro de Tec nología Animal (IVIA-

6 CITA), Polígono La Esperanza, Segorbe, Castellón, Spain

7 cInstitute of Science and Animal Technology, Laboratorio de Biotecnología de la

8 Reproducción, Universidad Politécnica de Valencia, Valencia, Spain

9

10 *Corresponding a uthor: Ra quel Lavara

11 lavara.raquel@gmail.com

12 Facultad de Veterinaria

13 Universidad Cardenal Herrera-CEU, CEU Universities

14 c/ Tirant lo Blanch, 7

1546115 Alfa ra del Patria rca (Va lencia)-Spa in

16 Tel. (+34) 96136 9000. Ext. 66014. Fax. (+34) 961395272.

17

18 
REVISED AND ACCEPTED

\section{ABSTRACT}

21 The aim of this study was to estimate the herita bility of semen freezability and to

22 estimate the genetic correlation between frozen-thawed sperm traits and the growth

23 rate in a patemal rabbit line. Estimated heritabilities showed that frozen-thawed

24 semen traits are heritable (ranged between 0.08 and 0.15 ). In the case of Live-FT

25 (percentage of viable sperm after freezing), the estimated heritability is the highest

26 one, and suggests the possibility of effective selection. After the study of genetic

27 correlations it seems that daily weight ga in (DG) wasnegatively correlated with spem

28 freeza bility, but no further conclusions could be drawn due to the high HPD95\%. More

29 data should be included in order to obta in betteraccuracy for the estimates of these

30 genetic correlations. If the results obtained at present study were confirmed, it would

31 imply that selection for DG could alter spem cell membranes or seminal plasma

32 composition, both components related to sperm cryoresistance.

33 Keywords: Rabbit-semen; Heritability; Genetic-correlation; Frozen-semen 
REVISED AND ACCEPTED

\section{INTRODUCTION}

Artificial insemination (AI) is used in rabbit industry, as in other species, to improve breeding management. In rabbit farms Al is performed with fresh or cooled semen rather than frozen because of the poor fertility resulting after tha wing [1]. However, frozen-thawed rabbit semen is used for conservation of banking resources (endangered breedsorhigh-value males); intema tional export (semen from selected lines) and research. The inter-animal, within species, variation in the ability of spermatozoa to survive cryopreservation is evident in many publications $[2,3,4,5]$, suggesting that spem freezability has a genetic component. In fact, selection experiments conducted on avian species showed that sperm freezability has a favourable selection response [6].

Recently in rabbits, Lavara et al. [7] provide estimates of repeata bility for some frozenthawed spem traits, indicating that sperm freezability in rabbits could be heritable. Previously, Mocé et al. [8], showed differences in fertility and prolific acy after Al with frozen-thawed semen from different selected rabbit lines. The line selected on the basis of growth rate during the fattening period, showed the lowest fertility and prolificacy, despite the fact that fresh semen from this line yielded high fertility and prolificacy rates. In this sense, knowledge of the genetic correlation between frozenthawed sperm traits and the selection criteria would allow us to predict the future correlated response on semen freeza bility on this selected rabbit line.

Therefore, the a ims of this study were to estimate the heritability of semen freezability traitsand to estimate the genetic correlation between frozen-tha wed sperm traitsand the growth rate in a patemal rabbit line.

\section{MATERIALS AND METHODS}

\subsection{Animals and experimental design}


59 Data were collected from 255 males belonging to a patemal rabbit line (Line R), bom between 2006 and 2007. Line R is a synthetic line that has been selected since 1980 for daily weight gain (DG) between 28 and 63 da ys of age by individua I selection [9]. This line was formed by crossing a Califomia line with a synthetic line created by mating commercial crossbred rabbits [10]. After weaning, animals were housed in collec tive cages (8 rabbits percage) subjected to a temperature ranging from 15 to $25 \circ \mathrm{C}$. At 63 days of age, the weight was recorded and males were moved to two Al stations. Males were placed in individual cages, subjected to a photoperiod of $16 \mathrm{~h}$ light/day and fed a d libitum with a commercial rabbit diet (on dry matter basis: $17.5 \%$ crude protein, 3.5\% ether extract, $16.7 \%$ crude fibre, $2938 \mathrm{kcal} / \mathrm{kg}$ ). In both stations, environmental conditions were controlled maintaining the temperature between 17 and $24^{\circ} \mathrm{C}$.

Malesbegan the training period at 150 to 170 days of age. The training wasperformed for two weeks. Aftertraining, the males started the production period. For the training and production period, two eja cula teswere collected permale and week on a single day using an artificial vagina, with a minimum of 30 min between collections. Collectionsfrom each male during the experiment were performed on the same day of the week. Only ejaculates that exhibited a white colour were used in the experiment. Samples containing urine and cell debris were discarded, whereas gel plugs were removed and the ejacula tes processed separately.

\subsection{Freezing-thawing protoc ols}

80 All the chemicals used were purchased from Sigma-Aldrich (Madrid-Spain). Sperm were cryopreserved by diluting the ejaculates 1:1 (v:v) with the freezing extender. The freezing extender was composed of Tris-citric acid-glucose $(0.25 \mathrm{M}$ of Tris(hyd roxymethyl)a minometha ne (Sigma, cat. no. T-1503), 88mM of a nhydrous citric acid (Sigma, cat. no. C-0759), and 47mM of D(+)glucose (Sigma, cat. no. G-8270)as 
base media, and 3.5 M of dimethyl sulfoxide (DMSO, Sigma, cat. no. D-5879) and 0.1 M of sucrose (Sigma, cat. no. S-8501), added as cryoprotectants [11]. All sperm manipulations were performed at $22^{\circ} \mathrm{C}$. The sperm were packaged in $0.25 \mathrm{~mL}$ plastic straws (IMV ${ }^{\circledR}$ Technologies, L'Aigle, France), sealed with modelling paste (J OVI, S.A. Barcelona, Spain, NRI 8-6650)and then cooled at 5ㄷ for $30 \mathrm{~min}$. Cooled temperature was provided storing straws in a refrigerator set at $5^{\circ} \mathrm{C}$. To freeze sperm, straws were suspended horizontally in liquid nitrogen vapour $5 \mathrm{~cm}$ above the liquid nitrogen level for 10 min before plunging into the liquid nitrogen $\left(\mathrm{LN}_{2}\right)$. The straws were kept in an $\mathrm{LN}_{2}$ bank until use. After storage in $\mathrm{LN}_{2}$, thawing was performed submerging the straws in a water bath at $44^{\circ} \mathrm{C}$ for $12 \mathrm{~s}$.

\subsection{Semen evaluation and traits}

Three traits were measured directly in frozen-tha wed semen: the percentage of viable sperm, the acrosome integrity and the sperm motility.

The percentage of viable (plasma membrane intact) sperm (Live-FT, \%) in each frozen-thawed sample was determined using flow cytometry, as described by Mocé et al. [12]. Briefly, a sample from each thawed straw was diluted with Tris-BSA to $30 \mathrm{x}$ $10^{6} \mathrm{sperm} / \mathrm{mL}$. Then, each sample was stained for flow cytometric a nalysis by transfering a $0.1 \mathrm{~mL}$ aliquot into a tube containing $0.45 \mathrm{~mL}$ Tris-BSA diluent, $2.5 \mu \mathrm{LSYBR}$ 14 (stock solution: $10 \mu \mathrm{M}$ in DMSO) and $2.5 \mu \mathrm{L}$ propidium iodide (PI) (stock solution: 1.5 $\mathrm{mM}$ in distilled water). The samples were incubated for $10 \mathrm{~min}$ at room temperature and filtered through a $40 \mu \mathrm{m}$ nylon mesh before being analysed using an Epics XLMCL flow cytometer (Beckman Coulter, IZASA, Barcelona, Spain) equipped with an argon laser tuned to $488 \mathrm{~nm}$ at $15 \mathrm{~mW}$ power. Fluorescence from 10,000 cells was measured using a 550 long pass filter (LP) combined with a $525 \mathrm{~nm}$ band pass filter (BP) to detect SYBR-14 and a $645 \mathrm{~nm}$ LP combined with a $620 \mathrm{Nm}$ BP filter to detect PI. Using this protocol, all cells sta in with SYBR-14, but only non-via ble cells stain with PI. 
111 For the acrosome status evaluation, an a liquot from each frozen-tha wed straw (20 $\mu \mathrm{L})$

112 was fixed with $180 \mu \mathrm{L}$ of a $0.2 \%$ solution of glutaraldehyde (Electron Microsc opy

113 Science, Wa shington) in Dulbecco's Phosphate Buffered Saline (DPBS). A minimum of

114100 spermatozoa were evaluated at X400 by phase positive contrast mic roscopy.

115 Acrosome status of normal sperm was classified as intact (AI) or reacted (AD). The

116 percentage of sperm with nomal a crosome status (Nar-FT, \%) wa s calcula ted as the

117 ratio: $[\mathrm{Al} /(\mathrm{Al}+\mathrm{AD})] \times 100$. For motility a nalyses, an aliquot from each frozen-tha wed

118 straw (10 $\mu \mathrm{L})$ was diluted 1:20 in an extender (Tris-citric acid-glucose) containing

119 bovine serum albumin $0.3 \%$ (BSA) to prevent the spermatozoa from sticking to the

120 glassware during the image capture analysis. Then, $10 \mu \mathrm{L}$ of the diluted sample were

121 placed into a $10 \mu \mathrm{m}$ deep Makler counting chamber (Sefi Medic al Instruments, Haifa,

122 Israel) for motility analysis using a computer-assisted sperm analysis (CASA) system

123 (Sperm Class Analyzer, S.C.A., Microptic, Barcelona, Spain). Sperm motility was assessed at $37^{\circ} \mathrm{C}$ with $\mathrm{X} 10$ negative phase contrast objective. Four mic rosc opic fields were captured for each sample, and then revised and correct manually in order to avoid the possible problems due to spem granules present in the rabbit semen plasma [13]. The percentage of total motile sperm cells (Mot-FT, \%) was recorded.

128 In addition, two synthetic traits were computed, the relative reduction of acrosome 129 integrity (Rnar, \%) and relative reduction of motility (Rmot, \%) after the freezing130 tha wing process. The two variableswere defined as the reduction of the tra it between 131 fresh and frozen-tha wed semen divided by the value of the trait in fresh semen.

132 A total of 12908 recordsforDG were used in the experiment. DG data used belonged

133 to animals from twelve generations before. In addition to DG, the sperm traits 134 described above were recorded involving 1292 ejaculates from 255 males. The 135 pedigree file included 14700 a nimals.

\section{$136 \quad 2.4$ Statistical analyses}


137 To reduce bias in the estimation of the genetic parameters of sperm traits resulting

138 from the selection for DG, the sperm traits were a nalysed jointly with DG [14]. A set of

139 two-trait a nalyses were thus performed to estima te the correlations among traits.

140 The mixed model used for the semen traits was:

$y_{s i j o p k l}=\mu_{s}+S_{s i}+O_{s j}+T_{s o}+P_{s p}+a_{s k}+p_{s k}+c_{s l}+e_{s j j o p k l}$

142 where $y_{\text {sjopk }}$ is the frozen-thawed semen trait recorded, $\mu_{s}$ is the overall mean, $S_{s i}$ is the

143 systematic effect station-year-season in which the ejacula te was collected, with 47

144 levels (two Al station with 28 and 19 weeks of collection for each one, where each

145 week of collection on each station represents one different level), $\mathrm{O}_{\mathrm{sj}}$ is the systematic

146 effect of ejacula te order with two levels (first and sec ond ejacula te on the same day),

$147 \mathrm{~T}_{\text {so }}$ is the systematic effect of tha wing session with 19 levels, $\mathrm{P}_{\mathrm{sp}}$ is the systematic effect

148 of age of the male with 3 levels ( $\leq 6$ months, $6-8$ months, more than 8 months), $a_{\text {sk }}$ is

149 the a nimal a dditive genetic effect, $p_{s k}$ is the perma nent environmental effect overall the ejaculates of the male $k, c_{s l}$ is the random effect of the litter in which the male $k$ was bom, and $e_{\text {sijopkl }}$ is the residual. It was assumed that the different random effects (additive, permanent, litter of birth and residual) followed nomal distributions and were independent among and within the effects, excepting the additive values of the a nimals, which were correlated though the numerator relationship matrix.

155 The mixed model used for DG was:

$y_{d i j k l}=\mu_{d}+b * S_{d l}+Y S_{d i}+O P_{d j}+a_{d k}+p_{d k}+C_{d l}+e_{d i j k l}$

where $y_{d i j k l}$ is the daily ga in of a nimal $k, \mu_{d}$ is the overall mean, $L S_{d l}$ is the covariate litter size $a t b i r t h ~ a n d ~ b$ the corresponding regression coeffic ient, $Y S_{d i}$ is the systema tic effect of year-season in which the animal was weaned, with 30 levels, OPdj is the systematic effect of parity order in which the a nimal was bom, with three levels (first, sec ond, and higher), $a_{d k}$ is the a nimal additive genetic effect, $c_{d l}$ is the random effect of the litter in which the animal $\mathrm{k}$ was bom; the residual of the model was split into two 
163

164

165

166

167

168

169

170

171

174

175

176

177

178

179

180

181

182

183

184

185

components: $p_{d k}$, which corresponds to the part of the residual correlated with the permanent environmental effect for semen tra its and $e_{d i j k l}$ that correspond s to the part of the residual unc orrelated with any other random effect, within and among tra its. The assumptions for the random effects for DG are the same as those indicated above for the semen traits.

Further assumptions, conceming correlations between random effects of DG $\left(a_{d}, p_{d}\right.$, $\left.c_{d}, e_{d}\right)$ and random effects of one semen trait $\left(a_{s}, p_{s}, c_{s}, e_{s}\right)$, a re summarized in the following matrices:

$$
\begin{gathered}
\mathbf{G}=\left[\begin{array}{cc}
\sigma_{a_{\mathrm{d}}}^{2} & \sigma_{a_{\mathrm{d}}, a_{\mathrm{s}}} \\
\sigma_{a_{\mathrm{s}} a_{\mathrm{d}}} & \sigma_{a_{\mathrm{s}}}^{2}
\end{array}\right] ; \\
\mathbf{P}=\left[\begin{array}{cc}
\sigma_{p_{\mathrm{d}}}^{2} & \sigma_{p_{\mathrm{d}}, p_{\mathrm{s}}} \\
\sigma_{p_{\mathrm{s}} p_{\mathrm{d}}} & \sigma_{p_{\mathrm{s}}}^{2}
\end{array}\right] ; \\
\mathbf{C}=\left[\begin{array}{cc}
\sigma_{c_{\mathrm{d}}}^{2} & \sigma_{c_{\mathrm{d}}, c_{\mathrm{s}}} \\
\sigma_{c_{\mathrm{s}} C_{\mathrm{d}}} & \sigma_{c_{\mathrm{s}}}^{2}
\end{array}\right] ; \\
\mathbf{R}=\left[\begin{array}{cc}
\sigma_{e_{\mathrm{d}}}^{2} & 0 \\
0 & \sigma_{e_{\mathrm{s}}}^{2}
\end{array}\right]
\end{gathered}
$$

where the components of $\mathbf{G}, \mathbf{P}, \mathbf{C}$ and $\mathbf{R}$ are the additive, permanent, litter of birth and residual variancesfor the daily gain and the semen trait in the diagonal, and the corresponding covariances between both traits, out of the diagonal.

A Bayesian framework was adopted for inference. Denote $\Omega$ as the vector including all the unknown parameters in the model. The joint posterior distribution of all para meters for the joint a nalyses of two traits was:

$p\left(\Omega \mid y_{s i j o p k l}, y_{d i j k l}\right) \propto p\left(y_{s i j o p k l}, y_{d i j k l} \mid \Omega\right) \times p(\Omega)$

Flat priors were used for systematic effects and variance components.

The following prior distributions for rand om effects were assumed:

$$
\mathrm{p}\left(\left[\begin{array}{c}
a_{\mathrm{d}} \\
a_{\mathrm{s}}
\end{array}\right] \mid \mathbf{G}\right) \sim \mathrm{N}(\mathbf{0}, \mathbf{A} \otimes \mathbf{G}), \mathrm{p}\left(\left[\begin{array}{c}
p_{\mathrm{d}} \\
p_{\mathrm{s}}
\end{array}\right] \mid \mathbf{P}\right) \sim \mathrm{N}(\mathbf{0}, \mathbf{I} \otimes \mathbf{P}), \mathrm{p}\left(\left[\begin{array}{c}
c_{\mathrm{d}} \\
c_{\mathrm{s}}
\end{array}\right] \mid \mathbf{C}\right) \sim \mathrm{N}(\mathbf{0}, \mathbf{I} \otimes \mathbf{C})
$$


Where $\mathbf{A}$ is the numerator relationship matrix off all the individuals, $\mathbf{0}$ is a vector of summarized a bove. The $\otimes$ symbol stays for the direct product.

The marginal posterior distributions of the parameters of interest were derived from the joint posterior density of all the unknowns. The Gibbs sampler algorithm was used to estimate the marginal posterior distributions of the systematic effects and the variance-covariance components implemented in the TM software developed by

193 Legarra et al. [15]. Deta ils of the fully conditional distributions of the model pa rameters, 194 can be found in Sorensen and Gianola [16].

195 After some exploratory a nalysis, chains of 3000000 iterations were used, with a buming period of 750000 . Only one sample of each 100 was saved. The convergence was checked on each chain by the ZGeweke criterion [17].

\section{RESULTS AND DISCUSSION}

Semen characteristics after the freezing-thawing procedures are summarized in Table1, where the dramatic reduction of sperm motility $(\mathrm{Rmot}=83 \%)$ and nomal acrosome status (Rnar=74\%) can be observed. For Mot-FT, Nar-FT and Live-FT, the means obtained are lower than the values reported for the same line in studies in which the ejaculates are preselected for cryopreservation $[8,12]$. Important differences of the present study were the assessment of ind ividual, rather than pooled ejaculates, and the lack of ejaculates pre-selection before freezing. The standard deviations obtained showed the high variability of these traits. In addition, some of them have an effect on male reproductive performance after AI [1].

\subsection{Repeatability, henitability, permanent and common litter effects}

Table 2 shows features of the estimated marginal posterior distributions (PM: posterior mean. HPD95\%: interval of highest density of $95 \%$ ) of heritability $\left(h^{2}\right)$; ratio of 
212 to phenotypic variance $\left(c^{2}\right)$ for frozen-tha wed semen. We computed the ratio of the 213 phenotypic variance due to the male effects (or repeatability) as the sum of $h^{2}, p^{2}$

214 and $c^{2}$ values. The estimates were moderate, ranging from 0.20 to 0.3 , being slightly 215 lower than the repea ta bilities of fresh semen tra its $[18,19,20]$, ind ic a ting the existence 216 of important individual variation for frozen-thawed semen traits in rabbits. Little 217 differences in frozen-thawed semen repeatabilities estimates were observed using a 218 subset sample of the present database [7], probably due to differences in the model 219 used and in the number of data. The main difference between studies is the decision 220 of using the information related to the selection criteria, at the present study we 221 included the information related to the selection process in orderto have a n unbia sed estimation of the variance components due to the fact that the DG and the frozenthawed traits could be correlated.

Estimated heritabilities showed that frozen-thawed semen traits are heritable (they ranged between 0.08 and 0.15 , Table 3 ). To our knowledge no previous heritability estimates for frozen-tha wed semen tra its in rabbits have been reported. The literature estima tes of herita bilities for correspond ing tra its in fresh semen were similar in the case of motility measured with CASA system (0.12-0.18 for Mot,\%; [19, 21, 22]) and slightly higher in the case of nomal acrosome status (0.18 for Nar,\%; [7]). The estimated heritability of Live-FT is the highest one and suggests the possibility of effective selection. To test this hypothesis, a divergent selection experiment should be conducted in order to ga in knowledge about the spem freeza bilty in rabbits, as well as to assess cryoresistance biological basis in rabbit semen. After 8 generations of selection in chicken, physiological changes and biochemical differences were reported between the selected line for frozen-thawed semen fertility and control line.

236 Sperm from the selected line had lower cholesterol and lower cholesterol:phospholipid ratio compared with control line, in addition seminal plasma 
238 cholesterol and phospholipid levels were lower in the selected line [6]. Regarding the proportions of variance due to the common litter effect, they are lower than the corresponding $h^{2}$ estimates. This result is in agreement with those published previously in related fresh semen traits [19].

\subsection{Comelations between spem traits and DG}

243 Estimates of genetic, permanent and litter comelations between DG and traits of

244 frozen-thawed semen are presented in Table 3.

245 Conceming permanent and litter correlations, the estimates were in general lower 246 than the genetic correlation and showed a great uncertainty associa ted with them.

247 Regarding genetic correlations, the estimates published previously show a ntagonistic 248 correlations between fresh semen traits as Nar (\%) and Mot (\%, objec tively mea sured) and DG [19]. In concordance, these traits after the freezing-thawing process must ma inta in a similar genetic correlation pattem. After the study of genetic correlations it seems that DG was negatively correlated with sperm freezability, but no further conclusions could be drawn due to the high HPD95\%. More data should be included in order to obtain better accuracy for the estimates of these genetic correlations. If

254 the results obtained at present study were confirmed, it would imply DG selection

255 could alter spem cell membranes or seminal plasma composition, both components 256 related to sperm cryoresistance. Therefore, the future knowledge of plasma 257 biochemistry characteristic s [23] and mitoc hondrial a c tivity of sperm cells [24] in this 258 selected line could be of great value. In fact, selection for DG in this rabbit line changed carcassfat levels at the same age compared with lines selected for litter size, and this would affect indirectly lipid membranes in sperm, or cholesterol: phospholipid ratio [25]. Estimates of genetic correlations between different semen traits and selection criteria in rabbits a re scarce (for a review see Piles et al. [26]), and estimates are generally imprecise making it 
diffic ult to draw reliable conclusions, so in the future more efforts should be done in order to better assess the genetic correlations.

\section{CONCLUSIONS}

267 From our study, it can be concluded that selection on semen freezability should be effec tive given the magnitude of herita bility estima tes in the present study. In addition there a re apparently nega tive effects of selection for increa sed growth rate on semen freezability. However, the uncertainty of obtained estimates diffic ults to make a prediction about the correlated effect of selection on sperm freezabilty with enough accuracy.

273

\section{ACKNOWFDGEMENTS}

This work wassupported by the Genera litat Valenciana research program (Prometeo

II 2014/036). Lavara R. acknowledges the partial support received from Generalitat

Valenciana under VALid program (APOST/2014/034) and from Ministry of Economy and Competitiveness under subprogramme "Formacion posdoctoral" (FPDI-201316707).

\section{REFERENCES}

282 [1] Mocé E, Vicente J S. Rabbit spem cryopreservation: A review. Anim Reprod Sci $283 \quad 2009 ; 110: 1-24$.

284 [2] Froman DP, Bemier PE. Identific ation of herita ble spermatozoa degeneration within the ductus deferens of the chicken (Gallus domestic us). Biol Reprod 1987;37:969-77.

286 [3] Willoughby, C.E., Mazur, P., Peter, A.T., C ritser, J.K., 1996. O smotic tolera nce limits and properties of murine spermatozoa. Biol. Reprod. 55, 715-27.

288 [4] Blesbois E, Seigneurin F, Grassea u I, Limouzin C, Besnard J , Gourichon D, Coquerelle 289 G, Rault P, Tixier-Boichard M. Semen cryoconservation for ex situ management of 
REVISED AND ACCEPTED

290 genetic diversity in chicken: Creation of the French avian cryobank. Poult Sci 2007;86:555-64.

292 [5] Long J A, Bongalhardo DC, Pelaéz J, Saxena S, Settar P, O'Sullivan NP, Fulton J E. Rooster semen cryopreservation: Effect of pedigree line and male age on postthaw sperm function. Poult Sci 2010; 89:966-73.

[6] Ansah GA, Buckland RB. Eight generations of selection for duration of fertility of frozen-thawed semen in the chicken. Poultry Sc i 1983; 62:1529-38.

297 [7] Lavara R, David I, Mocé E, Baselga M, Vicente JS. Environmental and male variation factors of freeza bility in ra bbit semen. Theriogenology 2013;79:582-89.

299 [8] Mocé E, Vicente JS, Lavara R. Effect of freezing-thawing protocols on the 300 perfomance of semen from three rabbit lines after artificial insemination. 301 Theriogenology 2003;60:115-23.

302 [9] Estany J, Camacho J, Baselga M, Blasco A. Selection response of growth rate in rabbits for meat production. Genet Sel Evol 1992;24:527-37.

[10] Piles M, Blasco A, Pla M. The effect of selection for growth rate on carcass composition and meat characteristic s of rabbits. Meat Sc ience 2000;54:347-55. [11] Vicente JS, Viudes de Castro M. A sucrose-DMSO extender for freezing rabbit semen. Reprod Nutr Dev 1996;36:485-92.

308 [12] Mocé E, Blanch E., Talavan A., Viudes De Castro MP. Effect of different freezing

309 velocities on the quality and fertilizing ability of cryopreserved rabbit spermatozoa.

310 Reprod Fertility and Development 2015;27:846-51.

311 [13] Castellini C, Lattaioli P, Cardinali R, Dal Bosco A. Effect of collection rhythm on 312 spermatozoa and droplet concentration of rabbit semen. World Rabbit Sci $313 \quad 2006 ; 14: 101-6$.

314 [14] Sorensen DA, J ohansson K. Estimation of direct and correlated responses to 315 selection using univa riate a nimal models. J Anim Sc i1992; 70: 2038-44. 
REVISED AND ACCEPTED

[15] Legarra A, Varona L, López de Maturana E. TM: threshold models.

317 http://cat.toulouse.inra.fr/ alegarra. 2008

318 [16] Sorensen DA, Gianola D. Likelihood, Bayesian, and MCMC methods in 319 quantitative genetics. Springer Science and Businness Media (2002), LLC, New York, 320 NY.

321 [17] Geweke J. Evaluating the accuracy of sampling-based approaches to the 322 calculation of posterior moments (with discussion). In: Bemardo J M., Berger J O., 323 Dawid AP., \& Smith AF. (Eds.). Bayesian statistic s 1992; 4: 169-93.

324 [18] Lavara R, Vicente JS, Baselga M. Genetic parameter estimates for semen 325 production traits and growth rate of a patemal rabbit line. J Anim Breed Genet $326 \quad 2011 ; 12: 44-51$.

327 [19] Lavara R, Vicente J S, Baselga M. Estimation of genetic parameters for semen 328 quality traits and growth rate in patemal rabbit line. Theriogenology 2012;78:567-75.

329 [20] Tusell L, Legarra M, García-Tomás M, Rafel O, Ramon J , Piles M. Genetic basis of 330 semen traits and their relationship with growth rate in rabbits. J Anim Sci 2012;90:1385331 97.

[21] Brun J M, Sanchez A, Duzert R, Sa leil G, Theau-Clément M. Pa ra mètres génètiques des caractéristiques de la semence de lapin. In: 13èmes J oum. Rech. Cunicole, Le Mans, France. 2009;11:17-8.

[22] Brun J M, Sanchez A, Ailloud E, Sa leil G, Theau-Clément M. Genetic parameters of rabbit semen traits and male fertilising ability. Anim Reprod Sci 2016;166:15-21. [23] Castellini C, Latta ioli P, Minelli A. Effect of seminal plasma on the characteristic S and fertility of rabbit spermatozoa. Anim Reprod Sc i 2000;63:275-82.

339 [24]Amaral A, Lourenco B, Marques M, Ramalho-Santos]. Mitochondria functionality and sperm quality. Reproduction 2013;146(5):R163-74 
341 [25] Hemández P, Ariñó B, Grimal A, Blasco A. Comparison of carcass and meat

342 characteristic s of three rabbit lines selected for litter size or growth ra te. Meat Sc ience $343 \quad 2006 ; 73: 645-50$.

344 [26] Piles M, Tusell L, Lavara R, Baselga M. Breeding programs to improve male 345 reproductive performance and efficiency of insemination dose production in 346 patemal lines: Feasibility and limitations (Review). World Ra bbit Sc i 2013; 21:61-75. 
365 Table 1: Crude mean and standard deviation for semen traits

\begin{tabular}{|l|l|l|l|}
\hline & $\mathbf{n}$ & Mean & $\begin{array}{l}\text { Standard } \\
\text { deviation }\end{array}$ \\
\hline Mot-FT & 1292 & 11.2 & 12.8 \\
\hline Nar-FT & 1227 & 22.4 & 16.6 \\
\hline Rmot & 1292 & 83.2 & 17.8 \\
\hline Rnar & 1227 & 74.5 & 18.3 \\
\hline Live-FT & 1199 & 30.0 & 19.5 \\
\hline
\end{tabular}

366 Mot-FT: percentage of motile spematozoa in frozen-thawed semen; Nar-FT: percentage of

367 spermatozoa with an intact acrosome in frozen-tha wed semen; Rnar: rela tive reduction of

368 spermatozoa with an intact acrosome,\%, Rmot: rela tive reduction of motile sperma tozoa, \%;

369 Live-FT: percentage of live spematozoa in frozen-thawed semen, \%. 
Table 2: Desc riptive statistic s of the posterior marginal distributions of heritability $\left(\mathrm{h}^{2}\right)$, ratio of permanent variance to phenotypic

variance $\left(p^{2}\right)$ and ratio of litter of birth variance to phenotypic variance $\left(c^{2}\right)$, for frozen-tha wed semen traits

\begin{tabular}{|c|c|c|c|c|c|c|}
\hline & \multicolumn{2}{|c|}{$h^{2}$} & \multicolumn{2}{|c|}{$\mathbf{p}^{2}$} & \multicolumn{2}{|c|}{$c^{2}$} \\
\hline & PM & HPD95\% & PM & HPD95\% & PM & HPD95\% \\
\hline Mot-FT & 0.13 & {$\left[\begin{array}{ll}0.02 & 0.25\end{array}\right]$} & 0.13 & {$\left[\begin{array}{ll}0.02 & 0.22\end{array}\right]$} & 0.03 & {$\left[\begin{array}{ll}0.00 & 0.09\end{array}\right]$} \\
\hline Nar-FT & 0.09 & {$\left[\begin{array}{ll}0.01 & 0.20\end{array}\right]$} & 0.11 & {$\left[\begin{array}{ll}0.02 & 0.21\end{array}\right]$} & 0.07 & {$\left[\begin{array}{lll}0.00 & 0.15]\end{array}\right]$} \\
\hline Rmot & 0.08 & {$\left[\begin{array}{lll}0.01 & 0.18\end{array}\right]$} & 0.11 & {$\left[\begin{array}{ll}0.02 & 0.19\end{array}\right]$} & 0.03 & {$\left[\begin{array}{ll}0.00 & 0.08\end{array}\right]$} \\
\hline Rnar & 0.11 & {$\left[\begin{array}{lll}0.01 & 0.21\end{array}\right]$} & 0.08 & {$\left[\begin{array}{ll}0.02 & 0.14\end{array}\right]$} & 0.05 & {$\left[\begin{array}{ll}0.00 & 0.13\end{array}\right]$} \\
\hline Live-FT & 0.15 & {$\left[\begin{array}{ll}0.04 & 0.26\end{array}\right]$} & 0.15 & {$\left[\begin{array}{ll}0.05 & 0.25\end{array}\right]$} & 0.02 & {$\left[\begin{array}{ll}0.00 & 0.06\end{array}\right]$} \\
\hline
\end{tabular}


375 Table 3: Desc riptive statistic s of the posterior ma rg inal distributions of the genetic $376\left(r_{g}\right)$, permanent $\left(r_{p}\right)$ and litter of birth $\left(r_{c}\right)$ correlations of daily gain (DG) with 377 frozen-thawed sperm traits.

378

\begin{tabular}{|c|c|c|c|c|c|c|}
\hline & \multicolumn{2}{|r|}{$\mathbf{r g}$} & \multicolumn{2}{|r|}{$r_{p}$} & \multicolumn{2}{|r|}{$\mathbf{r c}$} \\
\hline & PM & HPD95\% & PM & HPD95\% & PM & HPD95\% \\
\hline MotFI\&DG & -0.59 & {$\left[\begin{array}{ll}-1 & -0.12\end{array}\right]$} & -0.18 & {$\left[\begin{array}{lll}-0.86 & 0.50]\end{array}\right.$} & -0.24 & {$\left[\begin{array}{lll}-0.99 & 0.61]\end{array}\right.$} \\
\hline Nar-FI\&DG & -0.48 & {$\left[\begin{array}{lll}-0.98 & 0.24]\end{array}\right.$} & -0.36 & {$\left[\begin{array}{lll}-0.96 & 0.24\end{array}\right]$} & 0.11 & {$\left[\begin{array}{lll}-0.48 & 0.79\end{array}\right]$} \\
\hline Rmot\&DG & 0.31 & {$\left[\begin{array}{lll}-0.49 & 0.94]\end{array}\right]$} & 0.15 & {$\left[\begin{array}{lll}-0.61 & 0.86\end{array}\right]$} & 0.33 & {$\left[\begin{array}{lll}-0.45 & 1.00\end{array}\right]$} \\
\hline Rnar\&DG & 0.52 & {$\left[\begin{array}{lll}-0.07 & 0.98\end{array}\right]$} & 0.24 & {$\left[\begin{array}{lll}-0.50 & 1.00]\end{array}\right.$} & -0.22 & {$\left[\begin{array}{lll}-1.00 & 0.40]\end{array}\right.$} \\
\hline Live-FI\&DG & -0.44 & {$\left[\begin{array}{lll}-0.96 & 0.11]\end{array}\right.$} & -0.52 & {$\left[\begin{array}{lll}-0.99 & 0.06\end{array}\right]$} & 0.133 & {$\left[\begin{array}{lll}-0.58 & 1.00\end{array}\right]$} \\
\hline
\end{tabular}
motile spematozoa in frozen-thawed semen; DG: daily gain; Nar-FT: percentage of spermatozoa with an intact acrosome in frozen-thawed semen; Rnar: relative reduction of spematozoa with an intact acrosome,\%; Rmot: relative reduction of motile spematozoa, \%; Live-FT: percentage of live spematozoa in frozen-thawed semen, \%. 